\title{
Correlated Size Variations in Human Visual Cortex, Lateral Geniculate Nucleus, and Optic Tract
}

\author{
Timothy J. Andrews, Scott D. Halpern, and Dale Purves \\ Duke University Medical Center, Department of Neurobiology, Durham, North Carolina 27710
}

We have examined several components of the human visual system to determine how the dimensions of the optic tract, lateral geniculate nucleus (LGN), and primary visual cortex (V1) vary within the same brain. Measurements were made of the cross-sectional area of the optic tract, the volumes of the magnocellular and parvocellular layers of the LGN, and the surface area and volume of $\mathrm{V} 1$ in one or both cerebral hemispheres of 15 neurologically normal human brains obtained at autopsy. Consistent with previous observations, there was a two- to threefold variation in the size of each of these visual components among the individuals studied. Importantly, this variation was coordinated within the visual system of any one individual. That is, a relatively large $\mathrm{V} 1$ was associated with a commensurately large LGN and optic tract, whereas a relatively small V1 was associated with a commensurately smaller LGN and optic tract. This relationship among the components of the human visual system indicates that the development of its different parts is interdependent. Such coordinated variation should generate substantial differences in visual ability among humans.

Key words: visual system; primary visual cortex; lateral geniculate nucleus; optic tract; allometry; interindividual differences
Whether differences in human cognitive ability depend on brain size has been debated without resolution for more than a century (Morton, 1849; Pearl, 1906; Passingham, 1979; Gould, 1991; Peters, 1991; Rushton, 1992; Jensen, 1994). Perhaps because of the extraordinary scientific and political rancor generated by attempts to resolve this issue, it has rarely been mentioned that variation in the size of the human brain is relatively small compared with variation in the size of the various systems within it. For instance, although the overall size of the human brain (determined by weight) differs by $\sim 30 \%$ among normal subjects (Boyd, 1861; Pearl, 1905; Pakkenberg and Voight, 1964; Dekaban and Sadowsky, 1978), the areal extent of the somatosensory and motor cortices varies up to $100 \%$ (Penfield and Boldrey, 1937; Woolsey et al., 1979; White et al., 1997; for similar results in other species, see Merzenich et al., 1987; Riddle and Purves, 1995). This discrepancy is all the more remarkable because differences in brain volume (or weight) are necessarily reflected in lesser changes in brain surface area. The well defined function of some cortical regions, together with the marked interindividual variation in their size, raises the possibility of relating differences in the extent of particular cortical (or subcortical) regions to differences in specific sensory or motor abilities. This approach to assessing the relationship between behavior and the allocation of neural space would seem more plausible than comparing overall brain size with ill defined abilities assessed by "intelligence" tests.

One of the more extravagant interindividual variations in the human brain occurs in the primary visual cortex (Brodmann's area 17 , which we subsequently refer to as V1). In the early part of this

Received Nov. 7, 1996; revised Jan. 9, 1997; accepted Jan. 30, 1997.

This work was supported by National Institutes of Health Grant NS 29187. We thank Marybeth Groelle and Ann Richards for excellent technical assistance, Susan Reeves and Larry Hawkey for photographic support, Len White and David Riddle for helpful criticism of this manuscript, and Bill Wilkinson for advice on statistical analysis.

Correspondence should be addressed to Tim Andrews, Department of Neurobiology, Box 3209, Duke University Medical Center, Durham, NC 27710.

Copyright (C) 1997 Society for Neuroscience $0270-6474 / 97 / 172859-10 \$ 05.00 / 0$ century, several researchers showed that the surface area of V1 differs markedly among normal human subjects (Smith, 1904, 1906; Brodmann, 1909; Putnam 1926; Filiminoff, 1932). These findings were extended by Stensaas et al. (1974), who found, in a more comprehensive analysis, that the range of this interindividual variation in V1 area is approximately threefold (for comparable results in V1 volume, see Murphy, 1985; Klekamp et al., 1991; Leuba and Kraftsik, 1994). An equally striking result has been obtained by measurements of the human lateral geniculate nucleus (LGN), which shows a two- to threefold range in volume among individuals (Zworykin, 1980, 1981). Substantial variation is also apparent in the number of axons in the optic nerve (Balazsi et al., 1984; Johnson et al., 1987; Repka and Quigley, 1989), the number of retinal ganglion cells in a single eye (Curcio and Allen, 1990), and the density of photoreceptors in the retina (Curcio et al., 1987). Interestingly, marked interindividual differences in the extent of the V1 and other visual areas have been reported in studies of subhuman primates (Van Essen et al., 1981, 1984; Purves and Lamantia, 1993). Despite these observations, no one has investigated whether any of these related visual structures vary together in a single brain (or hemisphere), an issue that lies at the heart of understanding the functional consequences of a larger or smaller visual system in humans.

In this study, we have used various morphometric and cytoarchitectonic techniques to document how the sizes of three neural centers in the human visual system-the optic tract, LGN, and V1-vary within individuals, and whether such variations are coordinated. If particular humans are endowed with larger or smaller visual systems, and if such variations could be measured in vivo, one could then explore how the allocation of neural circuitry in a given brain influences visual performance.

\section{MATERIALS AND METHODS}

Brains from 15 neurologically normal subjects of both sexes were obtained at autopsy from the Duke University Medical Center in conformity with University guidelines and regulations (Table 1). The left hemisphere of one of these brains (Case 3) was damaged during the autopsy 


\begin{tabular}{|c|c|c|c|c|}
\hline Case no. & $\begin{array}{l}\text { Brain mass } \\
(\mathrm{gm})^{a}\end{array}$ & Gender & Height $(\mathrm{cm})$ & $\begin{array}{l}\text { Age at } \\
\text { autopsy (years) }\end{array}$ \\
\hline 1 & 1263 & $\mathrm{M}$ & 178 & 35 \\
\hline 2 & 1195 & $\mathrm{~F}$ & 157 & 64 \\
\hline 3 & 1316 & M & 180 & 83 \\
\hline 4 & 1125 & $\mathrm{~F}$ & 150 & 76 \\
\hline 5 & 1129 & $\mathrm{~F}$ & 162 & 76 \\
\hline 6 & 1144 & $\mathrm{~F}$ & 158 & 65 \\
\hline $7^{b}$ & 1288 & - & - & - \\
\hline $8^{b}$ & 1341 & - & - & - \\
\hline $9^{b}$ & 1375 & - & - & - \\
\hline 10 & 1256 & $\mathrm{M}$ & 168 & 86 \\
\hline 11 & 1196 & $\mathrm{~F}$ & 152 & 81 \\
\hline 12 & 1246 & M & 174 & 44 \\
\hline 13 & 1279 & $\mathrm{M}$ & 178 & 28 \\
\hline 14 & 1306 & M & 180 & 32 \\
\hline 15 & 1172 & $\mathrm{~F}$ & 173 & 36 \\
\hline Average \pm SD & $1242 \pm 76$ & & $167 \pm 11$ & $59 \pm 21$ \\
\hline
\end{tabular}

${ }^{a}$ Brains were weighed after fixation.

${ }^{b}$ The autopsy report number was accidentally erased from the containers that held these three brains in pathology lab.

and thus excluded. Five additional LGNs and two optic tracts were also damaged during brain removal. Thus, our final sample consisted of 24 hemispheres (including 11 complete brains) in which we made V1, LGN, and optic tract measurements; 29 hemispheres (including 14 complete brains) from which V1 area and volume were determined; 24 hemispheres (including 11 complete brains) in which LGN volume was measured; and 28 hemispheres (including 13 complete brains) in which the optic tract area was determined.

All brains were removed and placed in $10 \%$ formalin before further processing. The average time between death and fixation was under $12 \mathrm{hr}$ (mean \pm SEM $=11.7 \pm 1.7$ ), and the average time of fixation was $\sim 5$ months (mean \pm SEM $=4.8 \pm 0.9$ ). Brains were initially identified only by their autopsy case number; thus information relating to age, gender, and body height was unknown to us until the analysis was complete. Brains were weighed after the dura were removed. The brainstem and cerebellum were then removed, and the cerebral hemispheres were divided by a cut in the midline.

Optic tract. In the human visual system, axons from the ganglion cells of the nasal hemi-retina decussate at the optic chiasm, joining axons from the temporal hemi-retina of the other eye to form the optic tract in the ventrolateral diencephalon. Accordingly, each optic tract contains the retinal ganglion cell output that represents the contralateral visual field. Tissue blocks containing the LGN and optic tract were isolated by a series of cuts made from the medial surface of each hemisphere. The anterior portion of each optic tract (i.e., the part immediately posterior to the optic chiasm) was isolated and placed in $30 \%$ phosphate-buffered sucrose solution until fully submerged (1-2 weeks). The tissue was then embedded using a cardboard mold in a cryoprotectant (OCT Compound) and frozen quickly over dry ice; $40-\mu \mathrm{m}$-thick sections were taken in a plane orthogonal to the long axis of the tract at $480 \mu \mathrm{m}$ intervals. The flat surfaces of the cryoprotectant block were used to maintain orientation. Twenty sections from each tract were wet-mounted and stained with Gallyas silver stain to reveal myelin (Fig. 1). The sections were optically scanned and imported into NIH Image 1.58 (Wayne Rashband, National Institutes of Health, Bethesda, MD), and their cross-sectional areas were measured. To compensate for any variations of the tract along its length, we calculated the mean value from 20 sections over an extent of $9.6 \mathrm{~mm}$.

$L G N$. The human LGN comprises six histologically distinct layers that form a discrete and easily identifiable structure in the posterior thalamus. Optic tract axons originating in the nasal retina of the contralateral eye innervate layers 1,4 , and 6 of the LGN, and axons from temporal retina of the ipsilateral eye innervate layers 2, 3, and 5. A block of tissue containing the LGN was isolated by a coronal cut through the posterior portion of the optic tract near its junction with the LGN and processed in the same manner described above. Forty-micrometer-thick coronal sec- tions of the entire LGN were taken every $160 \mu \mathrm{m}$, mounted, and stained with $0.1 \%$ cresyl violet acetate for the demonstration of Nissl substance. The Nissl-stained sections of each LGN were optically scanned and imported into NIH Image, and the cross-sectional areas (including the interlaminar space) encompassed by the two ventral magnocellular layers and the four dorsal parvocellular layers were measured by tracing along the borders of these regions (Fig. 2). The interlaminar space between layers 2 and 3 was used to bisect the magnocellular and parvocellular regions, which are easily discernible by virtue of the much larger size and sparser distribution of cells in the magnocellular layers. To determine the volume of the magnocellular and parvocellular regions of the LGN, we used the equation

$$
V=d \sum_{i=1}^{n-1}\left(A_{i}+A_{i+1}\right) / 2,
$$

where $V$ is the estimated LGN volume, $d$ is the section interval, and $A_{i}$ and $\mathrm{A}_{i+1}$ are the cross-sectional areas of the LGN in adjacent sections (Uylings et al., 1986). The magnocellular and parvocellular volumes were then summed to provide a measure of total LGN volume.

$V 1$. The calcarine sulcus was identified in each hemisphere according to standard anatomical criteria (Ono et al., 1990) and photographed (Fig. $3 A$ ). The occipital lobe was then isolated by a coronal cut posterior to the splenium of the corpus callosum, cut into tissue blocks $\sim 1.5 \mathrm{~cm}$ thick, and processed in the same way as the optic tract and LGN. A pair of $50-\mu \mathrm{m}$-thick coronal sections through the occipital lobe were taken at 1 $\mathrm{mm}$ intervals and mounted for histological processing. One of the sections was stained for myelin, and the other for Nissl substance (see above). The myelin-stained sections of the occipital lobe highlighted the stria of Gennari (layer IVb), which delineates the extent of V1 (Fig. 3B). We also identified the boundaries of V1 cytoarchitectonically in the Nissl-stained sections to check the accuracy of measurements made according to the myelin-stained stria. Nissl staining highlights the celldense layer IVc and cell-sparse layers IVb and V that characterize V1 (Zilles, 1990). The abrupt end of layer IVb and the presence of large pyramidal cells in layer III (von Economo and Koskinas, 1925) define the V1/V2 border (Fig. 3C). The V1/V2 border determined in the myelinstained sections corresponded precisely to the border distinguished by Nissl staining.

After these sections were optically scanned and imported into NIH Image, the linear extent of V1 in each section was determined by tracing along the stria (Fig. $3 D$ ), and the total surface area of V1 was estimated by trapezoidal integration using the equation

$$
A=d \sum_{i=1}^{n-1}\left(L_{i}+L_{i+1}\right) / 2,
$$

where $A$ is the estimated cortical area, $d$ is the section interval $(1 \mathrm{~mm})$, and $L_{i}$ and $L_{i+1}$ are the measured lengths of cortical surface in adjacent sections (White et al., 1997). To assess the reliability with which these cytoarchitectonic boundaries could be recognized, two investigators independently traced sections of V1 in one brain. Corresponding length values were then compared using Pearson correlation tests. The correlation coefficient obtained in this way indicated good agreement between the two data sets $(r=0.94 ; p<0.0001)$; the absolute error between them was $<2 \%$.

To determine V1 volume, the extent of cortex from the pial surface to the gray matter/white matter border was traced and measured in each section. The total volume of V1 was then calculated using Equation 1. We also measured the linear extent of the cortical surface contained within the calcarine sulcus by tracing along the pial surface between the crests of the cuneus and the lingual gyrus (Fig. 3D). These linear measurements were entered into Equation 2 to provide an estimate of the cortical surface area within the calcarine sulcus.

Statistical analysis. Pearson product-moment correlations (StatView 4.1; Abacus Concepts, Berkeley, CA) were used to indicate the degree of covariance between the sizes of the optic tract, LGN, and V1 in different hemispheres (see Table 3). This analysis is used to describe the linear relationship between two variables. To assess the covariance of all the variables, principal components analysis was performed. Using this tool, we asked whether a single factor or multiple factors best explain the size variance of the several components of the visual system in the brains that we studied. 


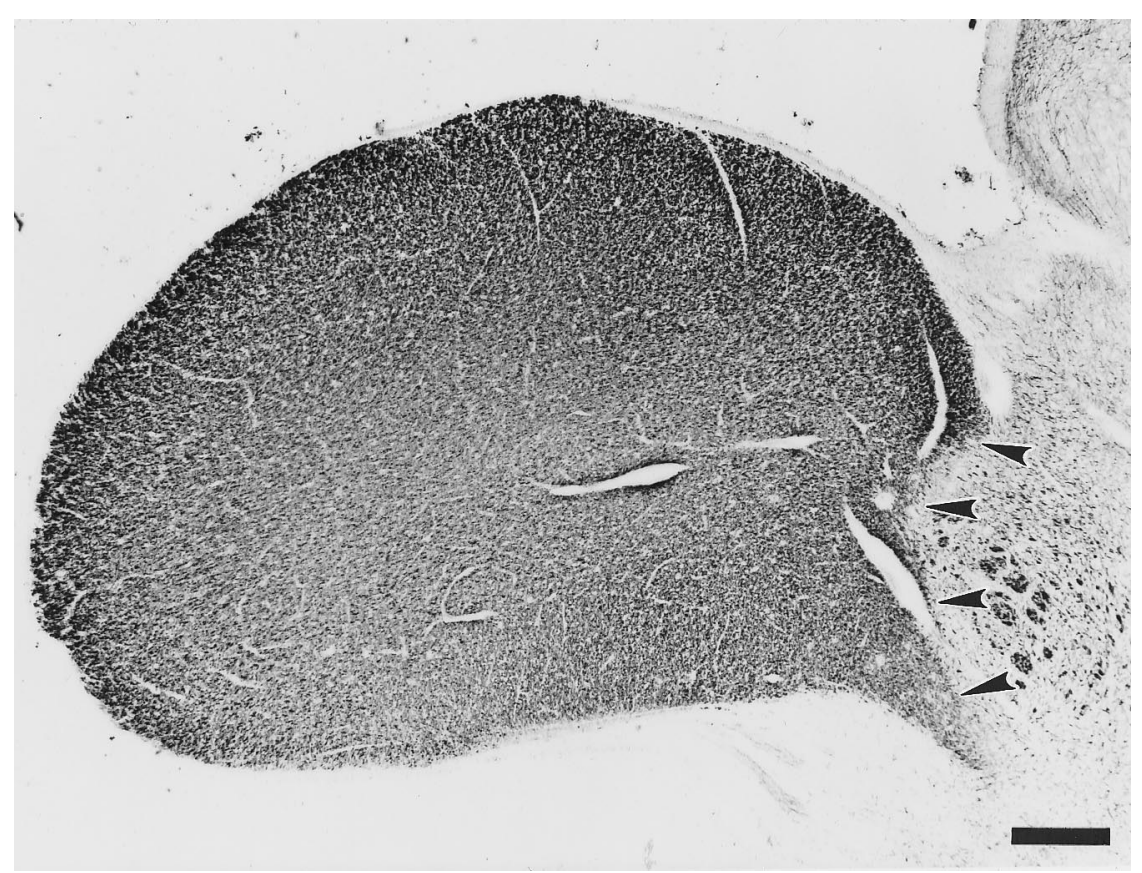

Figure 1. Photomicrograph of a cross-section through the right optic tract stained for myelin. The border between the optic tract and the surrounding tissue (arrowheads) is defined by a sharp change in the density of myelin staining, allowing precise delineation of the tract. Scale bar, $500 \mu \mathrm{m}$.

\section{RESULTS \\ Size variations in major components of the human visual system \\ Optic tract}

The mean cross-sectional areas of 28 individual optic tracts showed a more than twofold variation in size (right hemisphere $=$ $5.1-11.3 \mathrm{~mm}^{2}$, mean $=8.5 \mathrm{~mm}^{2}$; left hemisphere $=5.7-10.8 \mathrm{~mm}^{2}$, mean $=8.1 \mathrm{~mm}^{2}$ ) $($ Table 2$)$. An approximately twofold range in size was also apparent when the optic tracts were summed between corresponding hemispheres for 13 brains $\left(10.7-21.1 \mathrm{~mm}^{2}\right.$, mean $\left.=16.6 \mathrm{~mm}^{2}\right)$. Comparisons between hemispheres revealed no mean lateral bias in the size of the optic tract $(t=-1.3 ; p=$ 0.22 ). Although we are unaware of any similar analyses of the human optic tract, several investigators have analyzed the human optic nerve (Balazsi et al., 1984; Johnson et al., 1987; Repka and Quigley, 1989). These studies all reported significant variations in optic nerve area between individuals. For example, Johnson et al. (1987) found values ranging from 5.7 to $10.6 \mathrm{~mm}^{2}$ for the crosssectional areas of 13 optic nerves.

\section{$L G N$}

The LGNs measured from 24 hemispheres showed an approximately twofold variability in volume (right hemisphere $=91.1-154$ $\mathrm{mm}^{3}$, mean $=121 \mathrm{~mm}^{3}$; left hemisphere $=91.9-157 \mathrm{~mm}^{3}$, mean $=115 \mathrm{~mm}^{3}$ ). This observation is consistent with the results of Putnam (1926), who reported volumes from 77 to $115 \mathrm{~mm}^{3}$ for three human LGNs, and Zworykin (1980, 1981), who reported volumes of 66 to $152 \mathrm{~mm}^{3}$ for 17 nuclei. A similar interindividual variation was observed if LGNs were summed between corresponding hemispheres of 11 brains (range, $183-312 \mathrm{~mm}^{3}$; mean = 235). A paired $t$ test indicated no mean lateral bias in LGN volume $(t=-1.5, p=0.16)$. Our results also confirm Hickey and Guillery's (1979) observation that the number and shape of the layers vary widely both between LGNs and along the anteriorposterior extent of a single nucleus.

Variation in overall LGN volume was reflected by similar differences in both the magnocellular (right hemisphere $=23.0-$
$38.7 \mathrm{~mm}^{3}$, mean $=29.1 \mathrm{~mm}^{3}$; left hemisphere $=20.2-35.7 \mathrm{~mm}^{3}$, mean $=26.8 \mathrm{~mm}^{3}$ ) and parvocellular (right hemisphere $=68.2-$ $119 \mathrm{~mm}^{3}$, mean $=91.9 \mathrm{~mm}^{3}$; left hemisphere $=69.6-121 \mathrm{~mm}^{3}$, mean $=88.9 \mathrm{~mm}^{3}$ ) regions (Table 2). Variations in the volume of the magnocellular and parvocellular regions in each nucleus were closely related $(r=0.74 ; p<0.005)$. A corresponding variation was apparent when the magnocellular and parvocellular layers were summed between the hemispheres of 11 brains (magnocellular $=45-72 \mathrm{~mm}^{3}$; parvocellular $=138-239 \mathrm{~mm}^{3}$ ). In accord with previous studies that have noted that the magnocellular layers constitute a smaller proportion of the LGN than the parvocellular layers (Hickey and Guillery, 1979), the magnocellular layers in our sample occupied only $19-28 \%$ of the total LGN volume.

\section{V1}

In humans, the V1 is located nearly entirely on the medial surface of the occipital lobe, with approximately two-thirds of V1 lying within the walls of the calcarine sulcus (Stensaas et al., 1974) (Fig. $3 A$ ). Although we found, as have others (Brodmann, 1909; Polyak, 1957; Stensaas et al., 1974; Ono et al., 1990), that the course of the calcarine sulcus varies widely among individuals (and indeed between the two hemispheres of a given brain), the sulcus was always clearly identified on the medial surface of the hemisphere, as it continued anteriorly from its origin at or within a few millimeters of the occipital pole. In agreement with Stensaas et al. (1974), we found that the extent of V1 is greater, and proceeds farther anteriorly in the lingual gyrus, often extending beyond the junction between the calcarine and parieto-occipital sulcus.

The surface area of V1 showed an approximately two- to threefold size variation (right hemisphere $=1441-3221 \mathrm{~mm}^{2}$, mean $=2477 \mathrm{~mm}^{2}$; left hemisphere $=1438-3365 \mathrm{~mm}^{2}$, mean $=$ $2315 \mathrm{~mm}^{2}$ ) in 29 hemispheres (Table 2). This mean and range of variability are similar to those reported by Stensaas et al. (1974) in their analysis of 52 hemispheres (range, 1284-3702 $\mathrm{mm}^{2}$; mean $=$ $2134 \mathrm{~mm}^{2}$ ) and to earlier analyses of smaller samples (Smith, 1904, 1906; Brodmann, 1909; Putnam, 1926; Filiminoff, 1932). 


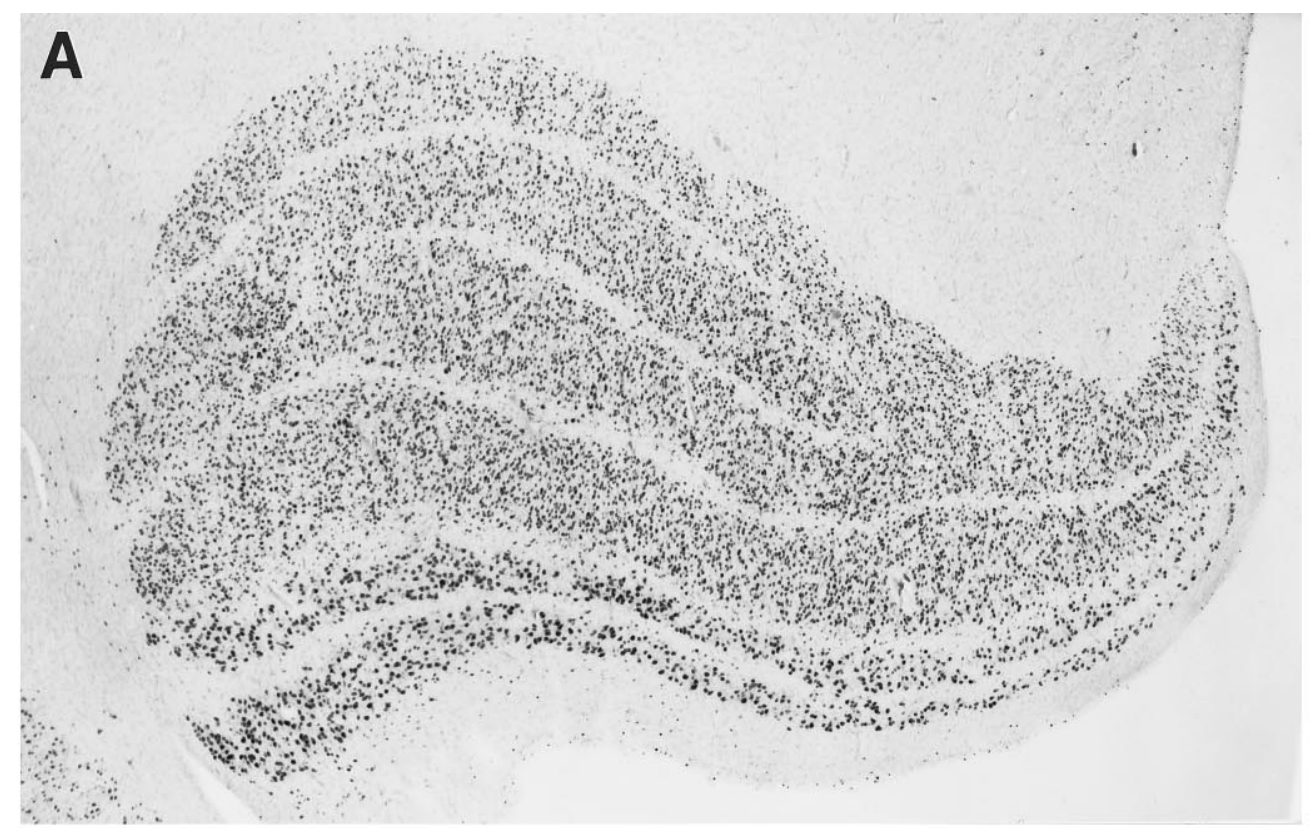

Figure 2. The human LGN and methods used to measure it. $A$, Photomicrograph of a coronal section of the left LGN stained for Nissl substance. $B$, Tracing of the section shown in $A$ demonstrating the distinctive laminar structure of the LGN. The magnocellular layers ( 1 and 2$)$ are discriminated from the parvocellular layers (3-6) by the much larger size of the constituent neurons and a diminished cell density. The areas (including the interlaminar space) encompassed by the two ventral magnocellular layers and the four dorsal parvocellular layers were measured by tracing along the borders of these regions. The interlaminar space between layers 2 and 3 was used to bisect the magnocellular and parvocellular regions. Scale bar, $1 \mathrm{~mm}$.

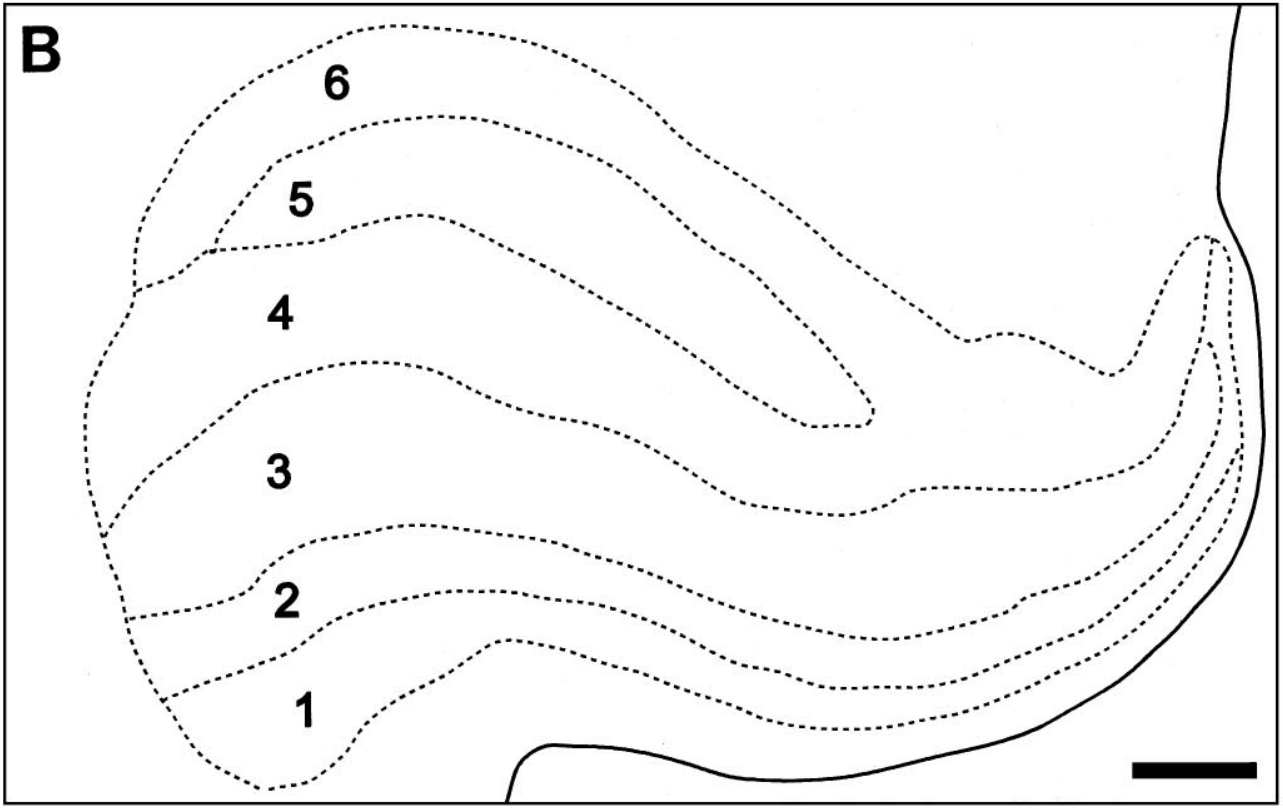

Summing the surface area of V1 for corresponding hemispheres in 14 brains also showed a more than twofold range of total individual V1 surface area (range, 2879-6586 $\mathrm{mm}^{2}$; mean $=4767$ $\mathrm{mm}^{2}$ ). Although 11 of 14 brains showed a right hemispheric asymmetry in V1 area, a paired $t$ test revealed no significant lateral bias $(t=1.1 ; p=0.30)$. Importantly, the area of V1 was significantly correlated with the cortical surface area within the calcarine sulcus $(r=0.68 ; p<0.01)$ (Fig. 4$)$. Thus the amount of cortical surface included in the calcarine sulcus provides a reasonable indication of V1 area. Because the calcarine sulcus can easily be seen by magnetic resonance imaging, this finding raises the possibility of making a simple structural measurement to assess the extent of $\mathrm{V} 1$ in vivo.

The volume of $\mathrm{V} 1$ demonstrated a more than twofold variation in size in 29 hemispheres (right hemisphere $=4272-7027 \mathrm{~mm}^{3}$, mean $=5692 \mathrm{~mm}^{3}$; left hemisphere $=3185-7568 \mathrm{~mm}^{3}$, mean $=$ $5119 \mathrm{~mm}^{3}$ ). A similar interindividual variation was detected when
V1 volume measurements were combined for corresponding hemispheres of 14 brains (range, $7769-14213 \mathrm{~mm}^{3}$; mean $=10770$ $\mathrm{mm}^{3}$ ). These values are somewhat higher than those reported by Murphy (1985) and Leuba and Kraftsik (1994). The area and volume of V1 within a hemisphere were found to correlate closely $(r=0.81 ; p<0.001)$. A significant right-hemispheric bias in V1 volume was present in 11 of 14 brains $(t=1.9 ; p<0.05)$; mean asymmetry $=13.7 \%$. A similar asymmetry in V1 volume was described by Murphy (1985), who suggested that this difference might underlie right hemisphere/left visual field superiority for a number of visual tasks (Kimura and Durnford, 1974).

\section{Overall brain size}

To compare variation in the visual system with differences in brain size, we measured hemispheric mass (excluding brainstem and cerebellum) in nine brains. In contrast to the marked variation in the visual system, hemispheric mass varied by only $18 \%$, ranging 

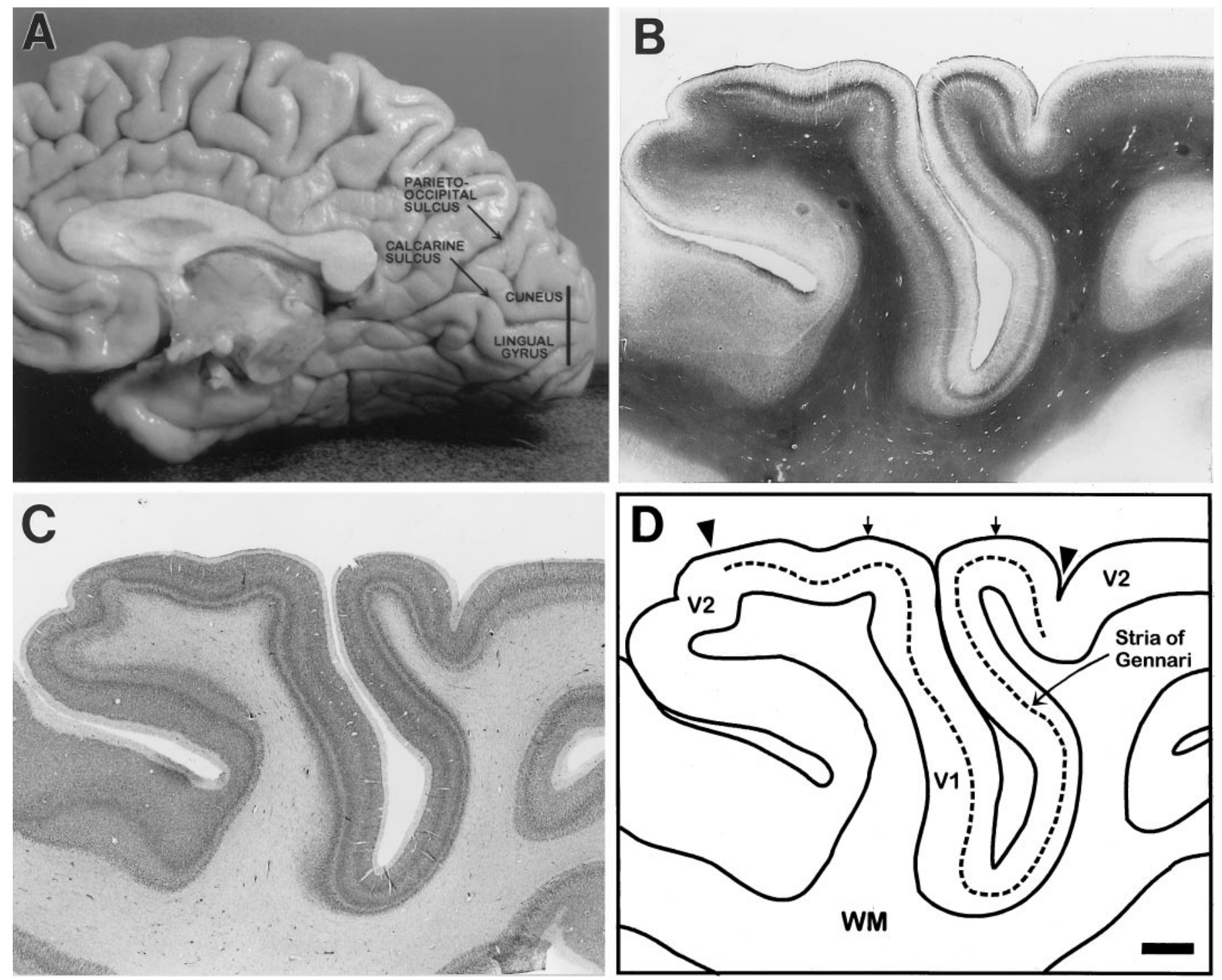

Figure 3. V1 and methods used to measure it. $A$, Photograph of the medial surface of the human occipital lobe showing the calcarine sulcus, the cuneus, and the lingual gyrus. The vertical line corresponds to the plane of section in $B$ and $C$. $B$, Photomicrograph of a coronal section through the cuneus and lingual gyrus, stained for myelin. The medial surface of the hemisphere is represented by the upper border of the section. V1 is defined by a densely stained band of myelin in layer IVb (the stria of Gennari). $C$, Adjacent Nissl-stained section shows prominent cell-dense layer IVc and cell-sparse layers IVb and $\mathrm{V}$ that distinguish V1. D, Tracing of the sections in $B$ and $C$ to identify the cortical parameters measured. The extent of V1 (arrowheads) was determined by tracing the stria (dashed line) in the myelin-stained section and confirmed by the cytoarchitecture of the Nissl-stained section. Volume measurements were made by tracing the boundaries of V1 from the pial surface to the gray matter/white matter (WM) border. The arrows indicate the tangent points of the lingual gyrus (left) and cuneus (right) from which the extent of the calcarine sulcus was measured. Scale bar, $2 \mathrm{~mm}$.

from 504 to $595 \mathrm{gm}($ mean $=547 \mathrm{gm})$. A similar variation was apparent if the measurements from two cerebral hemispheres were summed in a single brain (range, 1113-1180 gm). These results indicate that overall brain size does not account for the more substantial variation found in the visual system. Indeed, an $18 \%$ change in volume would be reflected by a smaller change in surface area.

\section{Correlation of structural variations along the retino-geniculo-cortical pathway}

Although marked interindividual differences in the sizes of the components of the visual system have been reported previously, no one has explored whether this variation is coordinated within a single brain. Consequently, we determined the degree of correlation between the sizes of the optic tract, LGN, and V1 in different individuals (Table 3; Fig. 5). If the sizes of these components of the visual system vary together, the measurement of $\mathrm{V} 1$, for example, would provide an index of the overall size of the primary visual system.

LGN volume was significantly correlated with both the volume $(r=0.78 ; p<0.005)$ and surface area $(r=0.79 ; p<0.05)$ of V1. Separate analysis of the magnocellular and parvocellular regions of the LGN showed a similar interrelationship (Table 3). The mean cross-sectional area of the optic tract was also significantly correlated with the volume of the LGN $(r=0.77 ; p<0.005)$ and with the volume of V1 (Table 3). A strong tendency for covariance was also apparent between the V1 and optic tract areas, although this did not achieve statistical significance. Because of the relatively small variation in brain size, we found, as expected, no 


\begin{tabular}{|c|c|c|c|c|c|c|}
\hline Hemisphere & $\begin{array}{l}\text { Hemisphere } \\
\text { mass }(\mathrm{gm})^{a}\end{array}$ & $\begin{array}{l}\text { Optic tract } \\
\left(\mathrm{mm}^{2}\right)\end{array}$ & $\begin{array}{l}\text { LGN-magno- } \\
\text { cellular }\left(\mathrm{mm}^{3}\right)^{b}\end{array}$ & $\begin{array}{l}\text { LGN-parvo- } \\
\text { cellular }\left(\mathrm{mm}^{3}\right)\end{array}$ & $\mathrm{V} 1$ area $\left(\mathrm{mm}^{2}\right)$ & $\begin{array}{l}\text { V1 volume } \\
\left(\mathrm{mm}^{3}\right)\end{array}$ \\
\hline $1 \mathrm{~L}$ & - & - & - & - & 2519.4 & 5125.9 \\
\hline $1 \mathrm{R}$ & - & 7.9 & - & - & 3155.2 & 7026.8 \\
\hline $2 \mathrm{~L}$ & - & 7.1 & - & - & 1438.5 & 3184.7 \\
\hline $2 \mathrm{R}$ & - & 8.2 & - & - & 1440.9 & 5782.6 \\
\hline $3 \mathrm{~L}$ & - & 9.6 & - & - & 2337.7 & 5468.5 \\
\hline $3 R$ & - & 11.3 & 30.5 & 85.9 & 2530.5 & 6512.8 \\
\hline $4 \mathrm{R}$ & - & 9.6 & 38.7 & 100.9 & 2929.3 & 6275.9 \\
\hline $5 \mathrm{~L}$ & - & 7.1 & 20.2 & 72.9 & 1854.1 & 4125.0 \\
\hline $5 \mathrm{R}$ & - & 7.4 & 24.7 & 78.8 & 2061.5 & 4684.7 \\
\hline $6 \mathrm{~L}$ & - & 5.7 & 27.9 & 72.3 & 2294.5 & 5019.0 \\
\hline $6 \mathrm{R}$ & - & 5.1 & 25.0 & 74.4 & 2395.8 & 5546.4 \\
\hline $7 \mathrm{~L}$ & 549 & 9.4 & 35.7 & 121.0 & 3075.0 & 6507.4 \\
\hline $7 \mathrm{R}$ & 555 & 10.1 & 36.4 & 118.5 & 2926.7 & 5982.3 \\
\hline $8 \mathrm{~L}$ & 575 & 10.8 & 32.7 & 111.2 & 3364.6 & 7567.9 \\
\hline $8 \mathrm{R}$ & 563 & 10.3 & 32.6 & 111.1 & 3221.2 & 6645.6 \\
\hline $9 \mathrm{~L}$ & 585 & 8.9 & 24.8 & 105.6 & 2342.8 & 5014.5 \\
\hline $9 \mathrm{R}$ & 595 & 9.6 & 23.6 & 94.6 & 2201.8 & 5463.6 \\
\hline $10 \mathrm{~L}$ & 528 & 6.7 & 26.4 & 80.5 & 2478.6 & 5037.5 \\
\hline $10 \mathrm{R}$ & 540 & 7.1 & 27.8 & 81.1 & 2620.0 & 5347.7 \\
\hline $11 \mathrm{~L}$ & 522 & 6.0 & 28.9 & 80.0 & 2389.8 & 5385.4 \\
\hline $11 \mathrm{R}$ & 512 & 8.2 & 31.3 & 92.5 & 2559.4 & 5820.2 \\
\hline $12 \mathrm{~L}$ & 542 & 7.4 & 22.3 & 69.6 & 1971.4 & 4528.3 \\
\hline $12 \mathrm{R}$ & 558 & 6.4 & 23.0 & 68.2 & 2073.8 & 4358.5 \\
\hline $13 \mathrm{~L}$ & 548 & 9.8 & 25.1 & 83.3 & 2151.6 & 5174.4 \\
\hline $13 R$ & 548 & 9.8 & 26.1 & 87.8 & 2281.3 & 5248.6 \\
\hline $14 \mathrm{~L}$ & 555 & 8.2 & 24.3 & 84.9 & 1683.0 & 3497.0 \\
\hline $14 \mathrm{R}$ & 557 & 8.0 & 26.6 & 90.6 & 1980.8 & 4272.0 \\
\hline $15 \mathrm{~L}$ & 504 & 8.9 & 26.8 & 94.0 & 2517.3 & 6038.2 \\
\hline $15 R$ & 509 & 8.5 & 31.4 & 110.3 & 2772.0 & 6424.0 \\
\hline
\end{tabular}

${ }^{a}$ For all but the first six brains in our series, the individual hemispheres were weighed separately.

${ }^{b}$ LGNs were dissected in all but the first two brains.

correlation between overall hemisphere mass and the size of these several components of the visual system (also see Leuba and Kraftsik, 1994) (Table 3).

Finally, we performed principal components analysis to determine whether the sizes of all the visual centers varied together. This analysis shows that most of the variance in the sizes of the components of the visual system among individuals can be ex- plained by one factor, meaning that their respective sizes covary to a surprising degree (Table 4). In contrast, only a small proportion of the variance in overall brain size could be explained by this factor, meaning that variation in overall brain size is independent of variation in the visual system. This finding also implies that differences in the size of visual cortex are compensated by commensurate changes in other brain regions.

Table 3. Matrix showing the Pearson product-moment correlations between various neural centers in the human visual system

\begin{tabular}{|c|c|c|c|c|c|c|}
\hline & $\begin{array}{l}\mathrm{V} 1 \text { area } \\
\left(\mathrm{mm}^{2}\right)\end{array}$ & $\begin{array}{l}\text { V1 volume } \\
\left(\mathrm{mm}^{3}\right)\end{array}$ & $\begin{array}{l}\text { LGN-magno- } \\
\text { cellular }\left(\mathrm{mm}^{3}\right)\end{array}$ & $\begin{array}{l}\text { LGN-parvo- } \\
\text { cellular }\left(\mathrm{mm}^{3}\right)\end{array}$ & $\begin{array}{l}\text { Optic tract } \\
\left(\mathrm{mm}^{2}\right)\end{array}$ & $\begin{array}{l}\text { Hemisphere } \\
\text { mass (gm) }\end{array}$ \\
\hline $\mathrm{V} 1$ area $\left(\mathrm{mm}^{2}\right)$ & - & & & & & \\
\hline V1 volume & 0.91 & & & & & \\
\hline$\left(\mathrm{mm}^{3}\right)$ & $(p<0.0001)$ & - & & & & \\
\hline Magnocellular volume & 0.87 & 0.81 & & & & \\
\hline$\left(\mathrm{mm}^{3}\right)$ & $(p<0.0001)$ & $(p<0.005)$ & - & & & \\
\hline Parvocellular volume & 0.74 & 0.74 & 0.80 & & & \\
\hline$\left(\mathrm{mm}^{3}\right)$ & $(p<0.01)$ & $(p<0.01)$ & $(p<0.005)$ & - & & \\
\hline OT area & 0.48 & 0.57 & 0.47 & 0.81 & & \\
\hline$\left(\mathrm{mm}^{2}\right)$ & $(p<0.15)$ & $(p<0.005)$ & $(p=0.15)$ & $(p<0.001)$ & - & \\
\hline Hemisphere mass & -0.03 & -0.09 & -0.18 & 0.22 & 0.46 & \\
\hline$(\mathrm{gm})$ & $(p=0.93)$ & $(p=0.81)$ & $(p=0.65)$ & $(p=0.59)$ & $(p=0.22)$ & - \\
\hline
\end{tabular}

Significance levels of the correlations are shown in parentheses. 


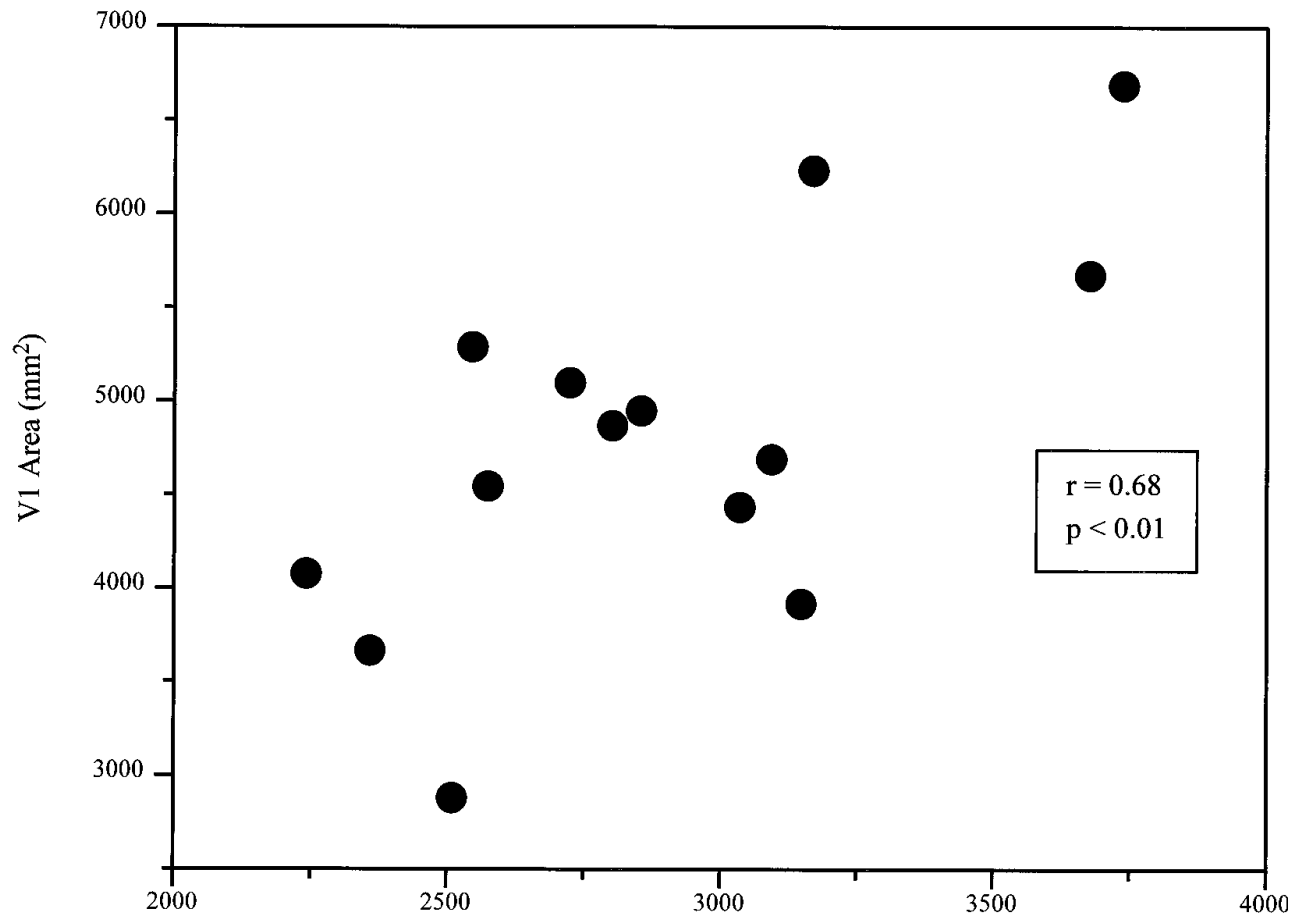

Calcarine Sulcus Area $\left(\mathrm{mm}^{2}\right)$

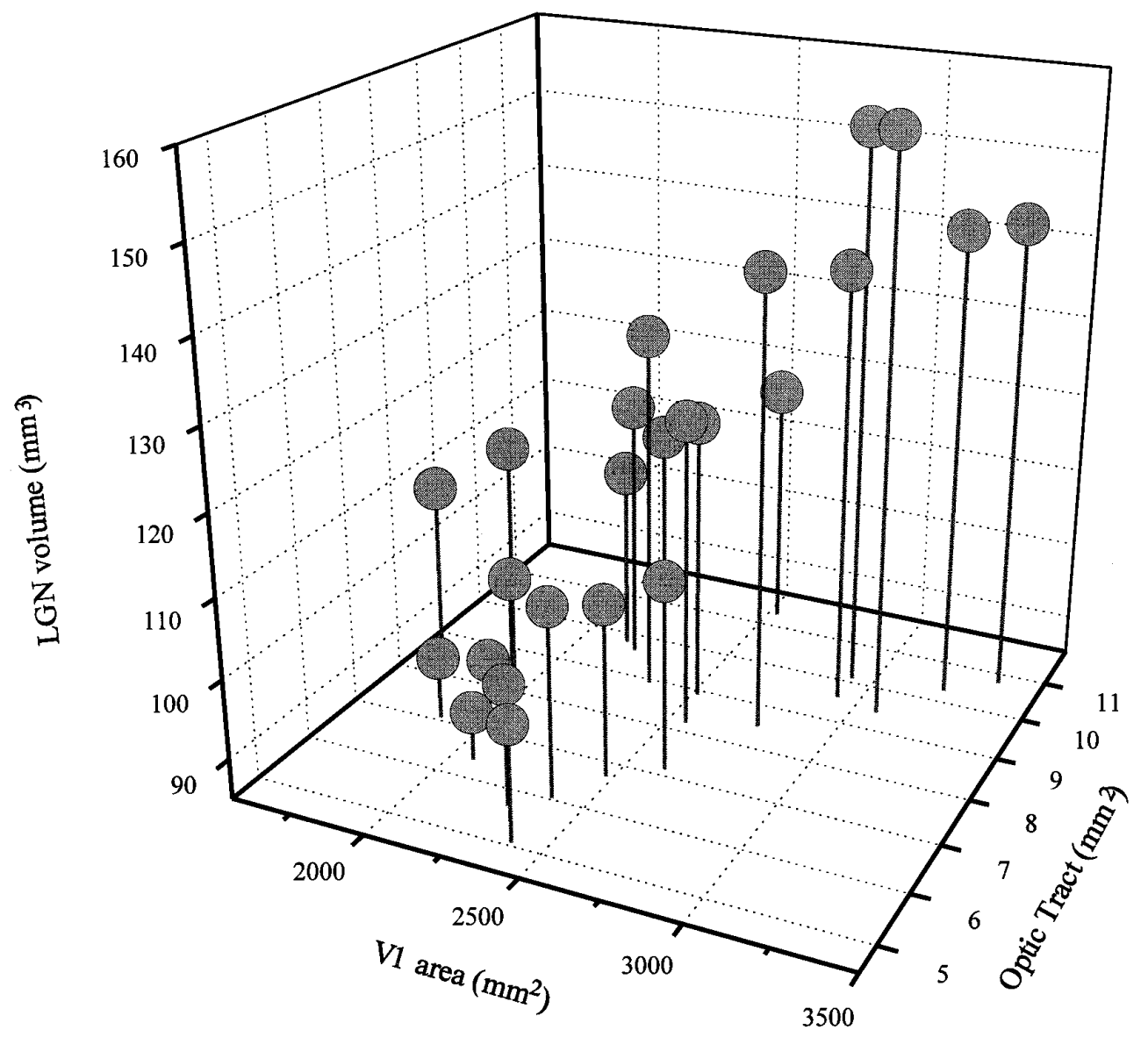

Figure 4. A scatter plot showing the correlation between the surface area of V1 and the surface area of the calcarine sulcus from both hemispheres in 14 brains. The strength of this correlation raises the possibility of being able to make a simple structural measurement using magnetic resonance imaging to assess the extent of V1 in vivo, which could then be compared with differences in visual ability.
Figure 5. Three-dimensional graph showing the relationship between the sizes of V1, LGN, and optic tract in 24 cerebral hemispheres. A strong correlation is apparent among these several components of the primary visual system. Thus, a small V1 tends to be associated with a relatively small LGN and optic tract, whereas a large V1 is associated with a commensurately large LGN and optic tract. 


\begin{tabular}{|c|c|c|c|c|c|c|}
\hline & $\begin{array}{l}\text { V1 area } \\
\left(\mathrm{mm}^{2}\right)\end{array}$ & $\begin{array}{l}\text { V1 volume } \\
\left(\mathrm{mm}^{3}\right)\end{array}$ & $\begin{array}{l}\text { LGN-magno- } \\
\text { cellular }\left(\mathrm{mm}^{3}\right)\end{array}$ & $\begin{array}{l}\text { LGN-parvo- } \\
\text { cellular }\left(\mathrm{mm}^{3}\right)\end{array}$ & $\begin{array}{l}\text { Optic tract } \\
\left(\mathrm{mm}^{2}\right)\end{array}$ & $\begin{array}{l}\text { Hemisphere } \\
\text { mass (gm) }\end{array}$ \\
\hline $\begin{array}{l}\text { Visual siz } \\
\text { factor }\end{array}$ & 0.93 & 0.93 & 0.88 & 0.92 & 0.76 & 0.1 \\
\hline
\end{tabular}

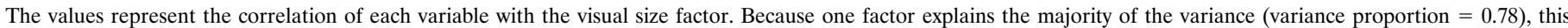

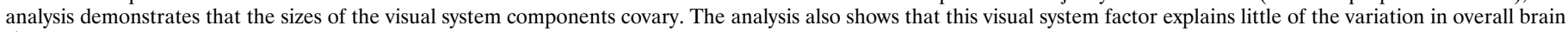
size.

\section{DISCUSSION}

The main findings of this study are that (1) the sizes of the optic tract, LGN, and V1 vary greatly among normal human brains; and (2) the sizes of each of these primary neural structures are strongly correlated within individuals. Thus a large V1 is generally associated with a large LGN and a large optic tract, and vice versa. The correlated variation of the magno- and parvocellular layers of the LGN suggests, moreover, that these differences are also apparent in the different submodalities of vision. Because the sizes of the structures studied did not covary with hemispheric mass, this relationship among visual components is not simply a function of overall brain size.

Macroscopic measures of visual structures, similar to those used in this study, have already been shown to provide reasonable indices of the underlying neural elements, including neuron number, dendritic complexity, and numbers of synapses. Evidence from our laboratory (White et al., 1997) and others (Barasa, 1960; Rockel et al., 1980; Galaburda et al., 1986; Szentagothai, 1993) indicates that sizable differences in the macroscopic structures of various parts of the nervous system are predicated on corresponding changes in the number of cellular elements in each region. That this general principle holds in the human visual system seems likely. Leuba and Kraftsik (1994) showed that average neuron density in V1 was remarkably consistent among individuals, implying that macroscopic differences will be reflected in corresponding changes in neuron number. Similarly, at the level of the optic nerve, the cross-sectional area is correlated with the number of axons comprising the nerve (Balazsi et al., 1984; Johnson et al., 1987; Repka and Quigley, 1989). These several studies suggest that differences in the number of basic neural elements underlie the quantitative variation in the gross structure of the visual system.

The importance of the coordinated variations in size of the visual system components that we report here ultimately concerns visual ability. Comparisons across species suggest that behaviors for which animals show particular proficiency are reflected in the amount of underlying circuitry (Johnson, 1980; Purves et al., 1996). In the visual system, for example, the amount of cortex specialized for the perception of form and color is proportionally greater in diurnal squirrel monkeys and macaque monkeys than in the nocturnal owl monkey (Kaas, 1993). Such variation in the allocation of cortical space has also been related to differences in visual acuity among primates (Cowey and Ellis, 1967; Rolls and Cowey, 1970). The link between visual performance and the allocation of neural space is further apparent in species in which a particular ability diminished or never developed fully in the course of evolution. For example, most subterranean mammals (e.g., moles and mole rats) and some bats have limited visual abilities, presumably because this sensory modality is of little use during a life spent underground or hunting in darkness. In such animals, the visual centers are markedly reduced in size compared with those found in members of related species who make more use of information conveyed by light, and visual performance is correspondingly poor (Burda et al., 1990; Cooper et al., 1993).

Perhaps the most compelling evidence for a relationship between neural circuitry and visual ability in humans is the comparison of central and peripheral visual function. The amount of neural space devoted to each degree of visual space decreases from central vision toward the periphery (Holmes, 1945; Daniel and Whitteridge, 1961; Horton and Hoyt, 1991; McFadzean et al., 1994). This reduction in neural space as a function of eccentricity is reflected in a decline in performance for various tasks. For instance, thresholds for vernier acuity (Levi et al., 1985; Virsu et al., 1987), contrast sensitivity (Virsu and Rovamo, 1979), motion detection (Levi et al., 1984), pattern sensitivity (Saarinen et al., 1989), and orientation discrimination (Paradiso and Carney, 1988; Rovamo et al., 1993) all increase markedly from central to peripheral vision. This decrease of visual performance with eccentricity seems to correlate more closely with the amount of cortical space devoted to each degree in the visual field than with the density of retinal receptors (Levi et al., 1985; Fahle and Schmid, 1988; Whitaker et al., 1992).

Despite the fact that previous investigations of vision in normal subjects have shown that specific human visual abilities vary substantially (Benton et al., 1978; Ginsburg et al., 1981; Yates et al., 1987; Roy et al., 1991; Nothdurft, 1993), no systematic analysis of these behavioral ranges has been reported. These limited observations, however, do raise the interesting question of whether the correlated variations we report in the sizes of the optic tract, LGN, and V1 are the basis for differences in individual visual ability. The wealth of knowledge about the visual system, and V1 in particular, along with its marked variation in size among individuals, makes human vision an especially attractive system for investigating whether proficiency in behavior is indeed instantiated by a commensurate allocation of neural circuitry. It seems likely that the correlated variation of the neural centers in the visual system that we report here will be reflected in similar differences in visual ability among humans.

\section{REFERENCES}

Balazsi AG, Rootman J, Drance SM, Schulzer M, Douglas GR (1984) The effect of age on the nerve fiber population of the human optic nerve. Am J Ophthalmol 97:760-766.

Barasa A (1960) Forma, grandezza e densita dei neuroni della corteccia cerebrale in mammiferi di grandezz corporea differente. A Aellforschung 53:69-89.

Benton AL, Varney NR, Hamsher KS (1978) Visuospatial judgment: a clinical test. Archiv Neurol 35:364-367.

Boyd R (1861) Tables of the weights of the human body and internal organs in the sane and insane of both sexes at various ages arranged from 2614 post-mortem examinations. Philos Trans 1:249-253.

Brodmann K (1909) Vergleichende Lokalisationslehre der Grosshirn- 
rinde in ihre Prinzipien dargestellt auf Grund des Zellenbaues. Barth, Leipzig.

Burda H, Burns V, Muller M (1990) Sensory adaptations in subterranean mammals. In: Evolution of subterranean mammals at the organismal and molecular levels (Nevo E, Reig OA, eds), pp 269-293. New York: Wiley.

Cooper HM, Herbin H, Nevo E (1993) Ocular regression conceals adaptive progression of the visual system in a blind subterranean mammal. Nature 361:156-159.

Cowey A, Ellis CM (1967) Visual acuity of the rhesus and squirrel monkeys. J Comp Physiol Psychol 64:80-84.

Curcio CA, Allen KA (1990) Topography of retinal ganglion cells in human retina. J Comp Neurol 300:5-25.

Curcio CA, Sloan KR, Packer O, Hendrickson AE, Kalina RE (1987) Distribution of cones in human and monkey retina: individual variability and radial asymmetry. Science 236:579-582.

Daniel PM, Whitteridge D (1961) The representation of the visual field of the cerebral cortex in monkeys. J Physiol (Lond) 159:203-221.

Dekaban AS, Sadowsky D (1978) Changes in brain weights during the span of human life: relation of brain weights to body heights and body weights. Ann Neurol 4:345-356.

Fahle M, Schmid M (1988) Naso-temporal asymmetry of visual perception and of the visual cortex. Vision Res 28:293-300.

Filiminoff IN (1932) Uber die Variabilitat der Grosshirnrindenstrukter: regio occipitalis beim erwachsenen Menschen. J Psychol Neurol 44:1-96.

Galaburda AM, Aboitz F, Rosen GD, Sherman GF (1986) Histological asymmetry in the primary visual cortex of the rat: implications for mechanisms of cerebral asymmetry. Cortex 22:151-160.

Ginsburg A, Cannon M, Sekuler R, Evans D, Owsley C, Mulvanny P (1981) Large population spatiotemporal contrast sensitivity functions. J Opt Soc Am [A] 71:1618.

Gould SJ (1991) The mismeasure of man. New York: Norton.

Hickey TL, Guillery RW (1979) Variability of laminar patterns in the human lateral geniculate nucleus. J Comp Neurol 183:221-246.

Holmes G (1945) The organization of the visual cortex in man. Proc R Soc Lond [Biol] 132:348-361.

Horton JC, Hoyt WF (1991) The representation of the visual field in human striate cortex. Arch Ophthalmol 109:816-824.

Jensen AR (1994) Psychometric g related to differences in head size. Pers Individ Differ 17:597-606.

Johnson BM, Miao M, Sadun AA (1987) Age-related decline of human optic nerve axon populations. Age 10:5-9.

Johnson JI (1980) Morphological correlates of specialized elaborations in somatic sensory cerebral cortex. In: Comparative neurology of the telencephalon. (Ebesson SOE, ed), pp 423-447. New York: Plenum.

Kaas JH (1993) The organization of the visual cortex in primates: problems, conclusions and the use of comparative studies in understanding the human brain. In: Functional organization of the human visual cortex (Gulyas B, Ottson D, Roland PE, eds), pp 1-11. New York: Pergamon.

Kimura D, Durnford M (1974) Normal studies in the function of the right hemisphere in vision. In: Hemisphere function in the brain ( $\mathrm{Di}$ mond S, Beaufort J, eds), pp 25-47. New York: Halstead.

Klekamp J, Riedel A, Harper C, Kretschmann HJ (1991) Quantitative changes during the postnatal maturation of the human visual cortex. J Neurol Sci 103:136-143.

Leuba G, Kraftsik R (1994) Changes in volume, surface estimate, threedimensional shape and total number of neurons of the human primary visual cortex from midgestation until old age. Anat Embryol 190:351-366.

Levi DM, Klein SA, Aitesbaomo AP (1984) Detection and discrimination of the direction of motion in central and peripheral vision of normal and amblyopic observers. Vision Res 24:789-800.

Levi DM, Klein SA, Aitesbaomo AP (1985) Vernier acuity, crowding and cortical magnification. Vision Res 25:963-977.

McFadzean R, Brosnahan D, Hadley D, Mutlukean E (1994) Representation of the visual field in the occipital cortex. Br J Ophthalmol 78:185-190.

Merzenich MM, Nelson RJ, Kaas JH, Stryker MP, Jenkins WM, Zook JM, Cynader MS, Shoppmann A (1987) Variability in hard surface representations in areas $3 \mathrm{~b}$ and 1 in adult owl and squirrel monkey. J Comp Neurol 258:281-296.

Morton SG (1849) Observations on the size of the brain in various races and families of man. Proc Natl Acad Natural Sci Philos 4:221-224.
Murphy GM (1985) Volumetric asymmetry in the human striate cortex. Exp Neurol 88:288-302.

Nothdurft HC (1993) The role of features in preattentive vision: comparison of orientation, motion and color cues. Vision Res 33:1937-1958.

Ono M, Kubik S, Abernathy CD (1990) Atlas of the cerebral sulci. New York: Georg Thieme Verlag.

Pakkenberg H, Voight J (1964) Brain weight of the Danes. Acta Anat 56:297-307.

Paradiso MA, Carney T (1988) Orientation discrimination as a function of stimulus eccentricity and size: nasal/temporal retinal asymmetry. Vision Res 28:867-874.

Passingham RE (1979) Brain size and intelligence in man. Brain Behav Evol 16:253-270.

Pearl R (1905) Biometrical studies in man. I. Variation and correlation in brain-weight. Biometrika 4:13-104.

Pearl R (1906) On the correlation between intelligence and the size of the head. J Comp Neurol Psychol 16:189-199.

Penfield W, Boldrey E (1937) Somatic motor and sensory representation in the cerebral cortex of man as studied by electrical stimulation. Brain 60:389-443.

Peters M (1991) Sex differences in human brain size and the general meaning of differences in brain size. Can J Psychol 45:507-522.

Polyak S (1957) The vertebrate visual system. Chicago: University of Chicago.

Purves D, LaMantia A-S (1993) The development of blobs in the monkey visual cortex. J Comp Neurol 334:169-175.

Purves D, White LE, Zheng D, Andrews TJ, Riddle DR (1996) Brain size, behavior and the allocation of neural space. In: Individual development over the lifespan: biological and psychosocial perspectives. (Magnusson D, ed), pp 162-178. Cambridge, UK: Cambridge UP.

Putnam TJ (1926) Studies on the central visual system. IV. The details of the organization of the geniculostriate system in man. Arch Neurol Psychiat Lond 16:683-707.

Repka MX, Quigley HA (1989) The effect of age on normal human optic nerve fiber number and diameter. Ophthalmology 96:26-31.

Riddle DR, Purves D (1995) Interindividual variation and lateral asymmetry of the rat primary visual cortex. J Neurosci 15:4184-4195.

Rockel AJ, Hiorns RW, Powell TPS (1980) The basic uniformity in the structure of the neocortex. Brain 103:221-244.

Rolls ET, Cowey A (1970) Topography of the retina and striate cortex and its relationship to visual acuity in rhesus monkeys and squirrel monkeys. Exp Brain Res 10:298-310.

Rovamo J, Makela P, Whitaker D (1993) Models of the visual cortex on the basis of psychophysical observations. In: Functional organization of the human visual cortex (Gulyas B, Ottson D, Roland PE, eds), pp 241-254. New York: Pergamon.

Roy MS, Podgor MJ, Collier B, Gunkel RD (1991) Color vision and age in a normal North American population. Graefes Arch Clin Exp Ophthalmol 229:139-144.

Rushton J-P (1992) Cranial capacity related to sex, rank and race in a stratified random sample of 6,325 U.S. military personnel. Intelligence 16:401-413.

Saarinen J, Rovamo J, Virsu V (1989) Analysis of spatial structure in eccentric vision. Invest Ophthalmol Vis Sci 30:293-296.

Smith GE (1904) The morphology of the occipital region of the cerebral hemisphere in man and the apes. Anat Anz 24:436-451.

Smith GE (1906) New studies on the folding of the visual cortex and the significance of the occipital sulci in the human brain. J Anat 41:198-207.

Stensaas SS, Eddington DK, Dobelle WH (1974) The topography and variability of the primary visual cortex in man. J Neurosurg 40:747-755.

Szentagothai JC (1993) Functional anatomy of human speech. Acta Neurochir (Wien) 56:17-19.

Uylings HB, van Eden CG, Hofman MA (1986) Morphometry of size/ volume variables and comparison of their bivariate relations in the nervous system under different conditions. J Neurosci Methods 18:19-37.

Van Essen DC, Maunsell JHR, Bixby JL (1981) The middle temporal visual area in the macaque: myeloarchitecture, connections, functional properties and topographic organization. J Comp Neurol 199:293-326.

Van Essen DC, Newsome WT, Maunsell HR (1984) The visual field representation in striate cortex of the macaque monkey: asymmetries, anisotropies, and individual variability. Vision Res 24:429-448. 
Virsu V, Rovamo J (1979) Visual resolution, contrast sensitivity and the cortical magnification factor. Exp Brain Res 37:475-494.

Virsu V, Nasanen R, Osmoviita K (1987) Cortical magnification and peripheral vision. J Opt Soc Am [A] 4:1568-1578.

von Economo C, Koskinas GN (1925) Die Cytoarchitektonik der Hirnrindedes erwachsenen Menschen. Berlin: Springer.

Whitaker D, Rovamo J, McVeigh D, Makela P (1992) Spatial scaling of vernier acuity tasks. Vision Res 32:1481-1491.

White LE, Andrews TJ, Hulette C, Richards A, Groelle M, Paydarfar JA, Purves D (1997) Structure of the human sensorimotor system II: lateral asymmetry. Cereb Cortex 7:31-47.

Woolsey CN, Erickson TC, Gilson WE (1979) Localization in somatic sensory and motor areas of human cerebral cortex as determined by direct recording of evoked potentials and electrical stimulation. J Neurosurg 51:476-506.

Yates JT, Harrison JM, O'Conner PS, Balentine C (1987) Contrast sensitivity: characteristics of a large young adult population. Am J Optom Physiol Opt 64:519-527.

Zilles K (1990) Cortex. In The human nervous system (Paxinos G, ed), pp 757-802. San Diego: Academic.

Zworykin VP (1980) Some new data on individual quantitative peculiarities of the human lateral geniculate body. Arch Anat Histol Embryol (Strasb) 3:27.

Zworykin VP (1981) Neuromorphological evidence of individual differences in human vision. Arch Anat Histol Embryol (Strasb) 10:24. 